\title{
Comparative Study of Prospective Delay Analysis Techniques (DATs)
}

\author{
Suroj Ghimire ${ }^{1}$, Anjay Kumar Mishra ${ }^{2 *}$
}

${ }^{1}$ NP Associates Pvt Ltd, Project controller, Nepal

${ }^{2}$ Associate Professor, Madan Bhandari Memorial Academy, Urlabari, Nepal

DOI: $10.36348 /$ SJCE.2019.v03i05.001 $\quad$ | Received: 15.08 .2019 | Accepted: 05.09.2019| Published: 11.09 .2019

*Corresponding author: Anjay Kumar Mishra

\section{Abstract}

Delays are the major sources of disputes and adverse relationships between the stakeholders in construction industry. The existing delay analysis techniques (DATs), though helpful for decision-making, have not succeeded in properly addressing the high incidence of disputes associated with delay claims resolutions. This research has made a comparative study of limitation and capabilities of different 'Prospective' DATs i.e., Impacted as Planned method and Time Impact Analysis Method under the same baseline program and under similar circumstances of delay occurrence through the case study of under-Construction Hydroelectric Project and review of the relevant issues not addressed by the techniques. Oracle's Primavera (P6) software has been used for delay analysis. The Contractor has not followed any of the DATs to raise the claim for extension of time. Though the contractor has submitted its revised construction schedule as per the FIDIC conditions of contract and ask for time extension of 721 days, the revised construction schedule has no any linkage with the original approved baseline Schedule. The Impacted as planned technique confined the delay to 621 days. The actual site condition and the progress were not considered in this method. The concurrent delays and pacing delays were also not addressed. According to the Time Impact analysis technique, the contractor's caused delay was 101 days and the delay from Employer's side was 529 days. The actual site condition and the progress were considered in this method. However, none of the Delay analysis techniques is found to address all the delay occurring events. The concurrent delays and pacing delayswere also not addressed. Time impact analysis technique is more accurate method as the site progress is incorporated in this method and is recommended to be followed.

Keywords: Impacted as Planned, Time Impact, Actual site Condition.

Copyright @ 2019: This is an open-access article distributed under the terms of the Creative Commons Attribution license which permits unrestricted use, distribution, and reproduction in any medium for non-commercial use (NonCommercial, or CC-BY-NC) provided the original author and source are credited.

\section{INTRODUCTION}

\section{BACKGROUND}

Construction delays are a main source of claims and disputes and have even been considered as the most common and costly cause of problems. Construction delays impart adverse impact on the success of the project in terms of time and cost. Its effect is confined not only to the construction industry alone, but also to the overall economy of a nation.

To substantiate the delay in Mega project is very complexin itself. The different methods that are used to provedelays, as explained in industry standards and handbooks, are theoretical and could be applied inthe small simple projects with few numbers of activities but the same methods cannot easily beapplied on mega/complex projects [1].

Barry [2], in his paper, presented on the international conference by the Society of Construction Law, mentioned that Impacted as-planned method,
Time impact analysis method, Collapsed as-built or 'but-for' analysis method, Snapshot/windows/ time slice analysis method, As-planned versus as-built windows analysis methods are commonly used delay analysis techniques. Inspite of the availability of these techniques, the most appropriate way to analyze the delays and causes of delay is still arguable subject. Arditi and Pattanakitchamroon [3] claimed that that none of the identified delay analysis methodology can be universally used in all situations, although they noted that the Windows Analysis/Time Impact Analysis is the most acceptable method and provides the most reliable results. Researchers have identified multiple factors affecting the selection and the results of the delay analysis methodology.

The assessment to raise the claim for extension of time is one of the serious issue. The Baseline Schedule is an important tool whereby delays are impacted in a systematic approach to find out the overall delay occurred in projects. Basically, the DATs 
needs to calculate the project delay to identify how much of it is attributable to each party (contractor or Employer) so that time and/or cost compensation can be decided. Delay analysis in sizable construction projects is complex and needs vigorous exercise. Especially concurrent delays are always the subject of discussion and/or argument between the concerned parties.

This study has reviewed the approved baseline construction schedule, the factors impacting the overall delay, the DATsusedby the contractor to claim for extension of time. The elaborated study has further been performed to find out the difference in project completion date using different industry standard DATs. The comparative discussion on the application of different techniques has thus helped to identify the capabilities and limitations of the different DATs

However, different DATs have got their unique application procedures and philosophies which may cause the different outcome for same delay causing events.

\section{RESEARCH OBJECTIVES}

The main purpose of this research is to make comparative study of the outcome of the different delay analysis techniques under the same baseline program and under similar circumstances of delay occurrence.

\section{LITERATURE REVIEW}

\section{Prospective and Retrospective Analysis Techniques}

Delay analysis techniques are either 'prospective' or 'retrospective'. Prospective analyses refer to the future, and seek to determine the likely impact of actual progress or a particular event(s) on project completion. Retrospective analyses refer to the historic, and usually seek to determine the actual impact of events upon progress and completion [2].

\section{Project Scheduling}

Bureau of Indian Standards [4] has defined Network Analysis and Scheduling as "the project network incorporating the activity durations and logical relationships with forward and backward pass schedule calculations to establish early and late start and finish time of activities with their available floats, critical activities, critical path and overall project duration." The project schedule needs to be prepared in terms of calendar dates of start and finish of activities with available floats. The network schedule is to be presented in the form of linked bar chart or in tabular format.

Society of Construction Law [5] has mentioned that the Contractor should submit and the Contract Administrator (CA) should accept a Programme (Using commercially available critical path method project planning Software) as early as possible showing the manner and Sequence in which the Contractor plans to carry out the Works. The accepted
Programme (Which then becomes the updated Programme) should be the means by which actual against the planned progress is monitored, and can be used as a tool for determining EoT. If the CA disagrees with the amount of the progress the Contractor considers it has achieved, it should notify the Contractor, and the CA and Contractor should the attempt to reach the agreement. If they do not agree, the CA's view should prevail unless and until overturned under the Contract dispute resolution procedures, and the CA's view on progress should be reflected in the updated programme.

The Sub Clause 8.3 of the Federation Internationale Des Ingenieurs-Conseils (FIDIC) [6] as cited in Mishra and Bhandari [7] General Conditions of Contract is about the Programme of the Works which states that the Contractor has to submit a detailed time programme to the Engineer within 28 daysafter receiving the notice for Commencement of Works. Whenever the previous programmeis inconsistent with actual progress or with the Contractor's obligations, a revised programme has to be submitted. According to this clause, the programme shall include:

- The order in which the Contractor intends to carry out the Works, including theanticipated timing of each stage of design (if any), Contractor's Documents,procurement, manufacture of Plant, delivery to Site, construction, erection andtesting,

- Each of these stages for work by each nominated Subcontractor

- The sequence and timing of inspections and tests specified in the Contract, and

- A supporting report which includes:

$>$ A general description of the methods which the Contractor intends to adopt, and of the major stages, in the execution of the Works, and

$>$ Details showing the Contractor's reasonable estimate of the number ofeach class of Contractor's Personnel and of each type of Contractor's Equipment, required on the Site for each major stage.

The Section B of the General Conditions of Contract of the Bidding Document for the Procurement of the Works prepared by Public Procurement Monitoring Office of Nepal [8] is related to the time control in which sub clause 26 provides guidelines on the Project Schedule as stated that within the time stated in the SCC, after the date of the Letter of Acceptance, the Contractor has to submit to the Project Manager for approval a Program showing the general methods, arrangements, order, and timing for all the activities in the Works.

\section{Progress Monitoring}

Bureau of Indian Standards [4] has defined the time monitoring as "processes implemented to collect, compile and analyze the status of project progress with 
respect to its baseline." The objective of time monitoring is to evaluate a deviation from the estimations made during time planning and its impact on project status. Reports generated through time monitoring analysis serves as a decision-making tool which are then input for project time control. Timely discharge of all contractual obligations by every project-stakeholder is essential for the success of project. Time schedule for each of these obligations which are indicated as distinct activities in the baselineschedule of time planning shall be monitored. Any variance is appropriately reported for effective contractadministration of the project.

The sub-clause 26.2 of the General Conditions of Contract of the Bidding Document for the Procurement of the Works prepared by Public Procurement Monitoring Office of Nepal [8] states that update of the program is a program showing the actual progress achieved on each activity and the effect of the progress achieved on the timing of the remaining work, including any changes to the sequence of the activities.

The sub-clause 26.3 states that the Contractor have to submit to the Project Manager for approval an updated Program at intervals no longer than the period stated in the SCC. If the Contractor does not submit an updated Program within this period, the Project Manager may withhold the amount stated in the SCC from the next payment certificate and continue to withhold this amount until the next payment after the date on which the overdue Program has been submitted.

\section{Delay Analysis Techniques}

There are various types of delay analysis techniques available.The carrying out of a successful delay analysis requires the preparation of areliable asplanned programme and an accurate as-built programme. The effectivenessof delay analysis techniques can be greatly increased when it can bedemonstratedthat the as-planned programme was reasonable [9].

Williams [10] considers that the network based methods are generally powerful and reliable to access the impact of delay in construction Projects. He explains that the main purpose of the delay analysis is to determine the cause, effect, responsibility and damages. Arditi and Pattanakitchamroon [3] suggest that four methods are the most common in the construction industry which are the as planned vs. as built analysis, Impacted as planned, collapsed as built and the windows analysis methods.

Barry [2] explained following five commonly used in delay analysis techniques:

1. Impacted as-planned method;

2. Time impact analysis method;

3. Collapsed as-built or 'but-for' analysis method;
4. Snapshot/windows/time slice analysis method;

5. As-planned versus as-built windows analysis method

Keane and Caletka [9] claimed that there lies greater extent of dissimilarities between the existing delay analysis techniques. There is much discussion about the various approachesto delay analysis along with explanations as to why it should not be surprisingwhen two opposing programming experts can apply the same techniqueand produce widely varying and inconsistent conclusions. The commonly applied scientific delayAnalysistechniques according to Keane and Caletka (2015) areimpacted as-planned, collapsed as-built, as-planned versus as-built, andtimeimpact analysis.

Barry [2] stated in his paper that there are effectively four main criteria for selecting which delay analysis methodology to use. These are:

- What does the contract require?

- Which approach is appropriate, correct, and sustainable?

- Does a lack of information preclude the use of any of the approaches?

- Do time/cost constraints eliminate certain options?

One principle that Barry [2] firmly support is that when analyzing delay to a project, one should establish the effect first (i.e. the incidence and extent of delay) and only then move to establish the cause of that delay. In such a manner both accuracy and objectivity are ensured. He further stated in his paper that there is a really need of sophisticated Computer generated Schedule. A CPM schedule allows us to quantify time on a priority basis (i.e. float), and this can provide very valuable insight to a stretched and stressed management team. The CPM schedule allows us to record on screen and paper what otherwise might exist only within the head of a valuable and experienced colleague.

\section{Brief Introduction of the Project under study}

The Madhya Bhotekoshi Jalavidyut Company Ltd. (MBJCL), a subsidiary of Chilime Hydropower Company limited of Nepal, is a public limited company established in 2010 AD to develop the Middle Bhotekoshi Hydroelectric Project (MBKHEP) of installed capacity 102MW. The MBKHEP is located in Sindhupalchowk District of Bagmati Zone of the central development region. The project is accessible by Araniko Highway at a distance of $101 \mathrm{~km}$ towards north-east of Kathmandu which could be reached in 3 hours' drive to head-works site at Chaku from Kathmandu.

The Project is basically a run-of-river type scheme having the capacity of $102 \mathrm{MW}$ with the design discharge of $50.8 \mathrm{~m} 3 / \mathrm{sec}$ and available gross head of $235 \mathrm{~m}$. 


\section{(Source: Project documents)}

Major Contract Packages

The Construction work has been splitted in three main contract packages:

- Lot 1 civil and hydro-mechanical works on EPC contract model.

- Lot 2 Electromechanical works on PDB contract model.

- Lot 3 Transmission line and substation on PDB contract model.

In addition there are other several small Contract packages that are associated with the Project. However, those contract packages are not linked to the major Construction Works. Those Contract Packages are:

- Contract for construction of Staff Quarters, office and access roads.

- Contract packages for landscaping works of the staff Quarter and office.

\section{LOT 1 -Civil and Hydro-mechanical Contract}

The LOT 1 Contract was awarded through International Competitive bidding (ICB) to the Chinese contractor Guangxi Hydroelectric Construction Bureau (GHCB). The contract agreement with the GHCB has been done on January $1^{\text {st }} 2014$ and the Commencement date was set on $11^{\text {th }}$ February 2014. The Contract is EPC Contract and has followed the FIDIC silver book. For Rock support and shotcrete Works BOQ system has been followed.

\section{RESEARCH METHODOLOGY Research approach}

Qualitative analysis research approach has been adapted in this research.

As this research is a specific and requires certain level of experience, the Questionnaire has been provided to the claim expert of the consultant. Correspondences related to the events giving rise to claims and baseline Schedule of the project under study has been carefully reviewed and analyzed.

\section{Study Area}

This is a case study research in which ongoing Project Middle Bhotekoshi Hydroelectric Project (MBKHEP) having capacity of 102 MW has been considered. The Consultant of the hydropower project under study has been selected as the respondent for this research. The approved baseline construction schedules, approved adjusted Schedules, delay impacted schedules at different stages of the project were also reviewed for further study.

\section{Data collection}

The primary data were used to find out the existing conditions of the project. The secondary data in the form of literature review sets the basis for using different prospective DATs under similar boundary conditions.

Following documents/components were studied in detail:

- The initial baseline program.

- Factors causing delays and its impact on the baseline Program.

- The delay analysis techniqueapplied in the revised program resubmitted by the Contractor asking for time extension for about two years after devastating earthquake occurred on April 2015 and the informal Blockade.

- The elaborated study has been performed to find out the difference in intended completion date using the

- Impacted as planned technique for delay analysis, and

- Time impact analysis technique for delay analysis.

Primary Data

Following are the data collected from the project:

1. Detailed Project Report (DPR) to find out the general information and Salient features of the Project.

2. FIDIC General Conditions of Contract and Particular conditions of Contract.

3. Approved Baseline Construction Schedule.

4. Series of correspondences between Employer, Consultant and the Contractor associated with the claims for extension of time, project change orders, variations etc.

5. Daily, weekly and monthly Progress reports.

6. Revised Schedule by the Contractor requesting for extension of time. The methods adapted has been reviewed and the redundant factors were identified.

Isolated, Contemporaneous and the Concurrent delays were segregated by reviewing those correspondences.

The objective type of questionnaire as well as the subjective questionnaire were asked to the respondent. The starting question for interviewee was "Explain how you decided on the method to assess delays in this project?" Depending on the answer of interviewee, a group of follow up questions were asked to gather the information about the project.

\section{Secondary Data}

Published articles, papers and books were the main source of Secondary Data collection. Reports, contract documents, theses, FCAN article and the various standards /Guidelines published also formed the part of secondary data. Secondary data were collected through literature review. The industry standard DATswere reviewed from the literature and those methods has been implemented to impact the delay. 
Since the project under study is on-going project, prospective methods of DATs were used.

The following DATs have been used in the approved baseline program under same boundary conditions and delays:

- Impacted as Planned Technique

- Time Impact Analysis Technique

\section{Data Analysis}

At first, correspondences related to the extension of time, schedules, differing site conditions, force majeure and the work stoppages was collected from the Project site office. Thus collected correspondences were reviewed thoroughly. Accordingly, the delays were classified as concurrent delay, contemporaneous delay and isolated delays. The employer's caused delays were tabulated and the impacted additional durations by those delays were calculated in the spreadsheet.

The FIDIC general conditions of Contract (GCC), Particular conditions of Contract (PCC) and the general specifications were observed thoroughly to find out the provisions made regarding construction time schedule and time extensions.

The progress reports were collected from the site office. The information obtained from completed questionnaires were also used during analysis of data.

The additional durations incurred due to isolated delay, concurrent delay and contemporaneous delay were impacted on the original baseline schedule by using impacted as-planned method and time impact analysis method.

The procedures applied in each method and the result of those methods were compared and discussed.

The project Planning Software Oracle's Primavera P6, Version 7 has been used for delay analysis.

\section{RESULTS AND DISCUSSION}

The delay analysis has further been done by using impacted as-planned method and Time Impact analysis technique under the same baseline program and under similar circumstances of delay occurrence. The comparative study of the limitations and capabilities of each method has been done in this chapter.

The case project under study is Middle Bhotekoshi Hydroelectric project having capacity of 102 MW.

\section{Construction Time Schedule}

The time allocated for this contract package is 1215 calendar days. The Commercial operation date of the Project was $9^{\text {th }}$ July 2017 as per approved Schedule.

\section{Construction schedule submitted by the contractor}

The Contractor submitted the program in accordance with the conditions of contract and the general specifications.

The contractor submitted the program to cover the entire schedule within the stipulated time period. i.e., 1215 days from the work commencement. The commercial operation date (COD) date of the program is $9^{\text {th }}$ June 2017. The detailed construction schedule is presented in Appendix 1.

\section{Features of the approved baseline construction Schedule \\ Formats and Settings}

- The Program has been prepared in the Project Planning Software Primavera P3.

- The calendar provided for activities in headworks is 7 days' workweek with 8 hrs.' per day and June-July-August-September as nonworking time.

- The calendar provided for activities in remaining works is 7 days' workweek with 8 hrs.' per day.

- Constraints were provided in the Site Handover activities of the Program.

- Critical path has been delineated in the Schedule.

- The activity coding has been done in the Program. Activities are grouped and sorted using activity codes rather than using WBS codes.

\section{Contents of the Schedule}

The Schedule has been prepared by using Critical Path method. The links has been provided in the activities.

Further to the conditions stated in the FIDIC Conditions of Contract, the activities for major stages of work, period for reviews, the timing for test and inspection as per the Contract has been delineated in the Program. Activities for Mobilization, Site access, equipment procurement, design submittals and approvals, major deliverables....etc. in addition to the major physical works has been shown in the Program.

The Project work has been divided into three separate construction areas, namely head-works, Water Conveyance System, and Powerhouse;

Activities for interfaces with the electromechanical works (by separate contractor) has been provided in the Program.

Resource loading has not been done in the Schedule.

Cost loading has not been done in the Schedule. The Construction program only provides the time sequence of the activities.Predecessors and 
Successors has been provided in every activities to avoid the dangling errors.

\section{Present Status of the Project}

Further referring the questionnaire with claim expert of the project, Mr. Krishna Prasad Regmi, it is found that the project has undergone several delays and the submitted program is now no longer workable. Substantial changes occurs in the construction Schedule. Following are the causes of the major delays:

\section{Delay caused from Employer side:}

1. Late handing over of the Head-works Site in time stipulated in the approved Construction Schedule.

2. Social issues in the ADIT 1 site, Powerhouse site and the head-works site. The Social problems has caused the substantial stoppage of the Works. The Contractor has notified each stoppages in writing.

Delay caused from Contractor side:

1. Inefficiency of the Contractor to mobilize its equipment in site in time.

2. Inefficiency of the Contractor to construct the batching plant and Aggregate crushing plant in the stipulated time period.

\section{Delay caused due to 'outside' factor:}

1. Massive Landslide occurred in Jure, around 10 $\mathrm{km}$ downstream of the Powerhouse on August 02, 2014.
2. The devastating earthquake occurred in $25^{\text {th }}$ April, 2015 and the series of aftershocks caused thereafter. This has caused the severe destruction and unrepairable elapse of time. The force majeure was declared in the project.

3. The "informal Blockade" by the India from September 2015. The shortage of the fuel due to the blockade caused the severe and significant loss in the Project.

The massive landslide in Jure blocked the entire transportation and hence the project work was literally closed. When the project was about to reinstate, the devastating earthquake occurred on $25^{\text {th }}$ April 2015. Due to earthquake, the work stopped completely. The temporary structures like laboratory building, access road to Adit, contractor's labour camp were affected severely. The Contractor then demobilized from the site. When the site was about to restart, the "blockade" by the India again forced the project to postpone its activities due to the shortage of the supplies (material and fuel). From 15 ${ }^{\text {th }}$ March 2016, the Contractor resumes the regular work.

\section{Major Delay events}

The delay events from the employer's side were identified and tabulated hereunder. Coding of each events have been done (D1, D2...etc) so as to make it easy to incorporate in the Schedule to impact delay.

Table-1: Delay type and description

\begin{tabular}{|c|c|c|c|c|}
\hline $\begin{array}{l}\text { Delay } \\
\text { Code }\end{array}$ & \multicolumn{2}{|c|}{ Description of the Delay } & \multicolumn{2}{|l|}{ Delay Duration (Days) } \\
\hline D1 & \multicolumn{2}{|c|}{$\begin{array}{l}\text { Employer asks for Counter Guarantee by "A" Class } \\
\text { commercial Bank of Nepal. The provision for Advance } \\
\text { payment guarantee was not in the Contract Agreement. The } \\
\text { Contractor ask to shift the commencement date from January } \\
15,2014 \text { to February } 11,2014 \text {. The Employer agreed to shift } \\
\text { the Commencement date accordingly. The new } \\
\text { commencement date was then February 11, 2014. Hence EOT } \\
\text { granted is } 28 \text { days. }\end{array}$} & \multicolumn{2}{|l|}{28} \\
\hline \multicolumn{5}{|c|}{ 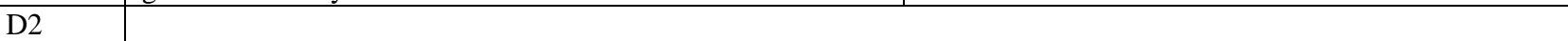 } \\
\hline & Area & Planned Handing over Date & Actually Handed over on & \\
\hline D2.1 & \multirow[t]{14}{*}{ Delay on part } & 11 April 2014 & 19 May 2014 & Site No. 3 \\
\hline $\mathrm{D} 2.2$ & & 11 April 2014 & 7- May-2014 & Site No.4 \\
\hline $\mathrm{D} 2.3$ & & 11 April 2014 & 19-Mar-2014 & Site No.5 \\
\hline $\mathrm{D} 2.4$ & & 11 April 2014 & 7-May-2014 & Site No.6 \\
\hline D2.5 & & 11 April 2014 & 7-May-2014 & Site No.7 \\
\hline D2.6 & & 11 April 2014 & 19-Mar-2014 & Site No.8 \\
\hline D2.7 & & 11 April 2014 & 7-May-2014 & Site No.9 \\
\hline D2.8 & & 11 April 2014 & 6-May-2014 & Site No.10 \\
\hline $\mathrm{D} 2.9$ & & 11 April 2014 & 7-May-2014 & Site No.11 \\
\hline $\mathrm{D} 2.10$ & & 11 April 2014 & 6-May-2014 & Site No.12 \\
\hline $\mathrm{D} 2.11$ & & 11 April 2014 & 5-Jun-2014 & Site No.13 \\
\hline $\mathrm{D} 2.12$ & & 11 April 2014 & 5-Jun-2014 & Site No.14 \\
\hline D2.13 & & 11 April 2014 & 5-Jun-2014 & Site No.15 \\
\hline $\mathrm{D} 2.14$ & & NA & 6-May-2014 & Site No.16 \\
\hline $\mathrm{D} 2.15$ & Delay on part & NA & 31-May-2014 & Access Road to ADIT 1 \\
\hline D2.16 & Delay on part & 11 April 2014 & Not yet handed over & Head-works site \\
\hline D2.17 & Delay on part & 11 April 2014 & 02-Aug-2014 & Power House site \\
\hline
\end{tabular}




\begin{tabular}{|c|c|c|c|}
\hline D2.18 & Spoil disposal area & 11 April 2014 & \\
\hline D3 & \multicolumn{2}{|c|}{ Stoppage of Works at Access Roads to Adit 1 and Adit 2, } & 3 \\
\hline D4 & \multicolumn{2}{|c|}{ Impact on Construction works due to interruption of Araniko Highway. } & 47 \\
\hline D5 & \multicolumn{2}{|c|}{ Notice to claim by the contractor due to construction work stoppage by the villagers } & 10 \\
\hline D6 & \multicolumn{2}{|c|}{$\begin{array}{l}\text { Stoppage of work due to private house locating at the middle of the road in November 03, } \\
2014 \text {. }\end{array}$} & 1 \\
\hline D7 & \multicolumn{2}{|c|}{ Stoppage of gabion work @ access road to Adit 1 by Local villager in November 10, 2014.} & 1 \\
\hline D8 & \multicolumn{2}{|c|}{$\begin{array}{l}\text { The work stopped entirely at access road to Adit } 1 \text { from October 30, } 2014 \text { to November 21, } \\
2014\end{array}$} & 21 \\
\hline D9 & \multicolumn{2}{|c|}{ The Work was stopped from 1st December 2014 to 4th December 2014.} & 4 \\
\hline D10 & \multicolumn{2}{|c|}{ The Work at Adit 1 stopped from December 04, 2014 to December 08, 2014.} & 5 \\
\hline D11 & \multicolumn{2}{|c|}{ Work Stopped at Site no.14 from 10 December 2014 to 12 December 2014.} & 3 \\
\hline D12 & \multicolumn{2}{|c|}{ Work Stopped at ADIT 1 from December 112014 to December 12,2014 } & 2 \\
\hline D13 & \multicolumn{2}{|c|}{ The Work at Adit 1 stopped from March 12, 2015 to March 15, 2014.} & 4 \\
\hline D14 & \multicolumn{2}{|c|}{$\begin{array}{l}\text { The work on the whole site stopped due to massive Earthquake occurred on April } 25 \text {, } \\
\text { 2015. The Force majeure was declared and the Contractor demobilized their entire set up }\end{array}$} & $(174+151)$ \\
\hline
\end{tabular}

\section{Source: Regmi, 2016, personal Communication based on project documents [11]}

\section{Contractors claim for Extension of time}

It was found that the contract document has made a provision to prepare revised construction schedule if the substantial changes occurs. In this regard, the contractor submit the revised construction schedule effective from the $15^{\text {th }}$ March 2016 asking for the time extension for about 2 years. According to the new construction schedule, the intended completion date was $17^{\text {th }}$ May 2019. The following table provides a clear comparison:

Table-2: Comparison of Approved and Contractor's proposed completion date

\begin{tabular}{|l|l|ll|}
\hline & $\begin{array}{l}\text { As per approved Baseline } \\
\text { Program }\end{array}$ & As per Proposed Revised Program \\
\hline Project Completion & $9^{\text {th }}$ June 2017 & $31^{\text {st } M a y ~ 2019 ~}$ & \\
\hline Project Duration & 1215 days & $\begin{array}{l}1936 \text { days (From original } \\
\text { Commencement date) }\end{array}$ & \\
\hline Additional days proposed: (1936-1215 )=721 days & & \\
\hline
\end{tabular}

\section{Source: Regmi, 2016, personal Communication [11]}

The program was prepared by using the software Primavera Project Planner (P3).

The contractor has not used any of the established DATs. The Durations provided for the critical activitieswere not found consistent with the approved baseline Schedule. There were no any linkage between the original approved base schedule and the revised schedule.

\section{Delay Analysis by using impacted as-Planned method}

The overall delay in the project was further analyzed by using impacted as-planned method.It is 'prospective' and 'dynamic' method of delay analysis.
The delays that are caused from the employer's side, delays caused due to the factors which were beyond the control of the employer and the contractor and the concurrent delays are considered for further analysis. The total float of the activities has been considered in this analysis.

The approved original Schedule is kept as baseline Schedule. It is to be noted here that the Primavera P6 has provided the option to manage multiple baseline projects as well.

The delay events were introduced into the schedule, and linked to the activities affected by those delay events. 


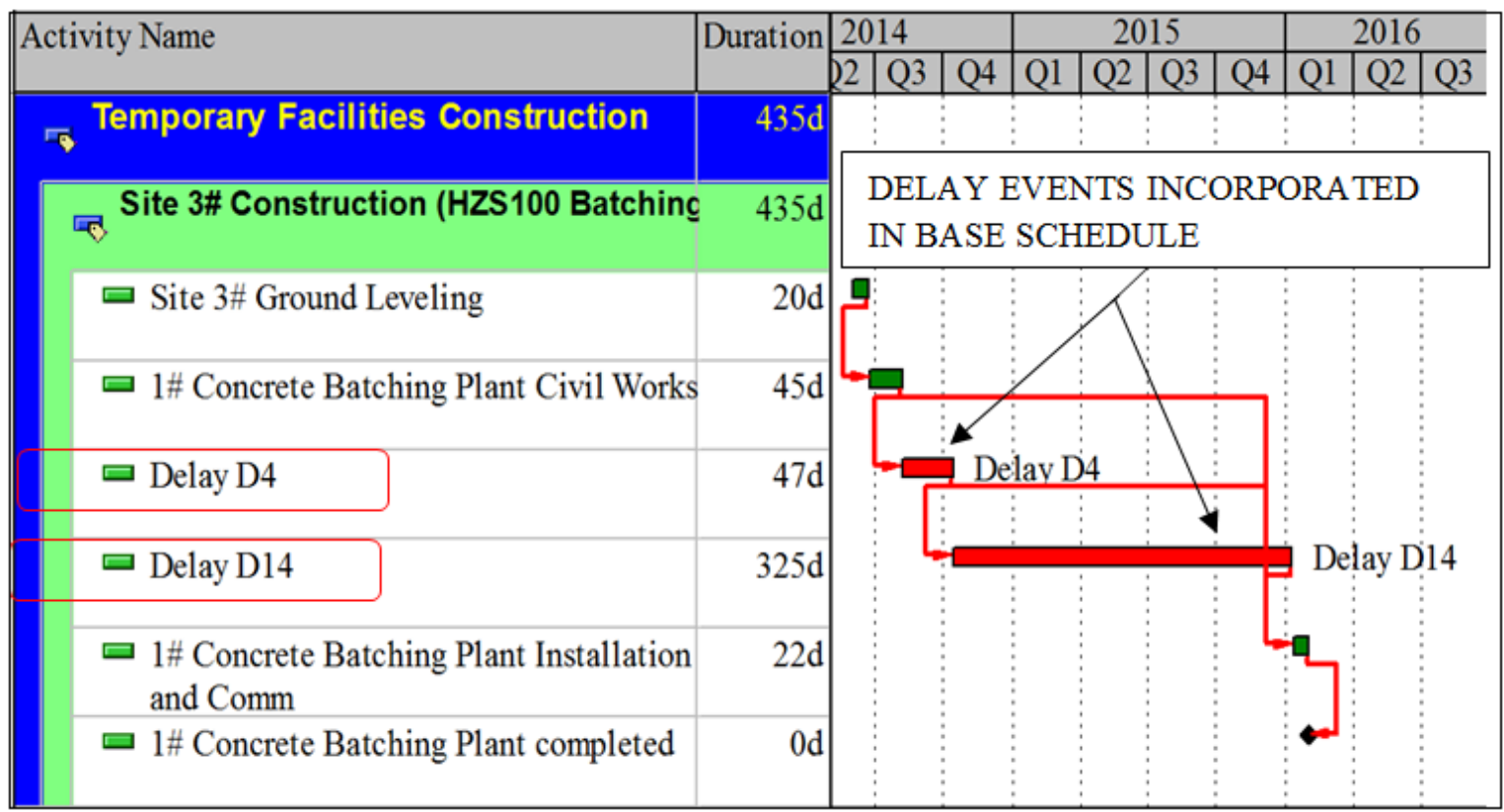

Fig-1: Illustration-Insertion of Delay Activities

Referring series of correspondences between the employer and the contractor, the delay events (D1 to D14), the effected duration and the area impacted by those delays were identified which is presented in Table-1 above.
In case of milestones like handing over of site, right of access to the site, partial completion ...etc, delays are impacted by putting constraints over those activities.

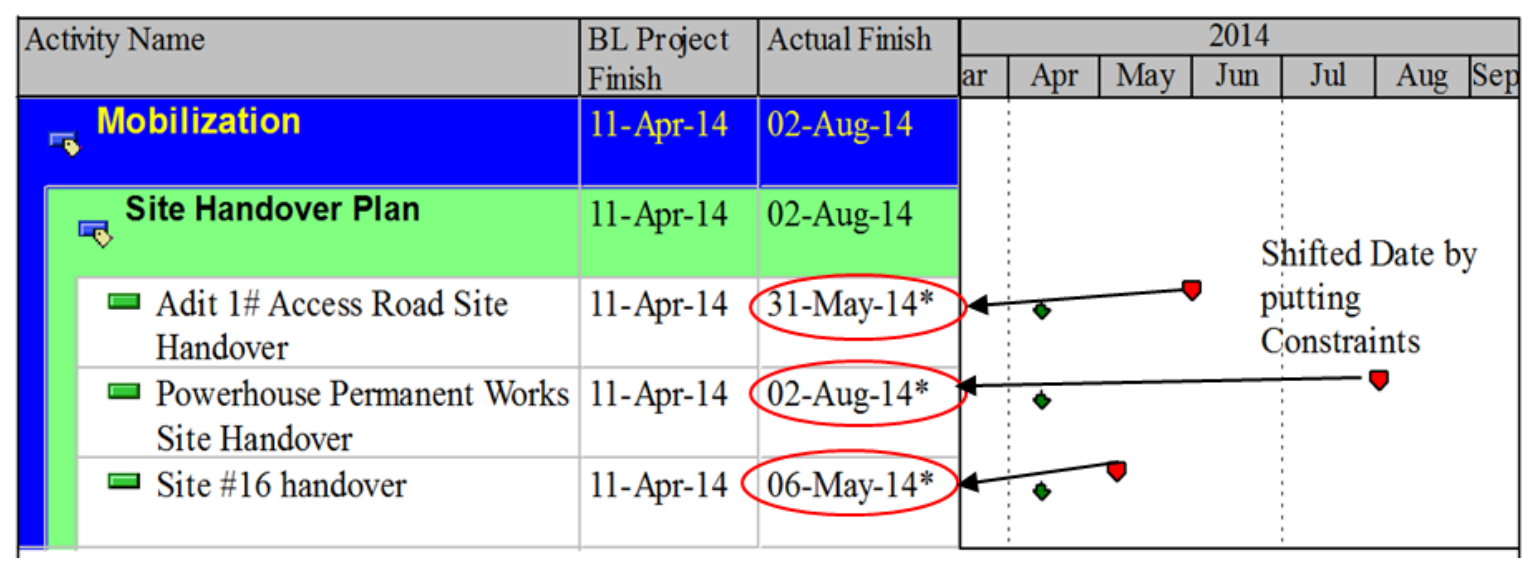

Fig-2: Illustration-Insertion of constraints on the activities

\section{Changes made in the original baseline Program}

The Delays mentioned in Table-1 above (D1 to D14) and the delay in Handover of the sites (In the form of Constraints) were all incorporated in the baseline program as shown in the table: 
Table-3: List of Delayed events -Impacted as planned method

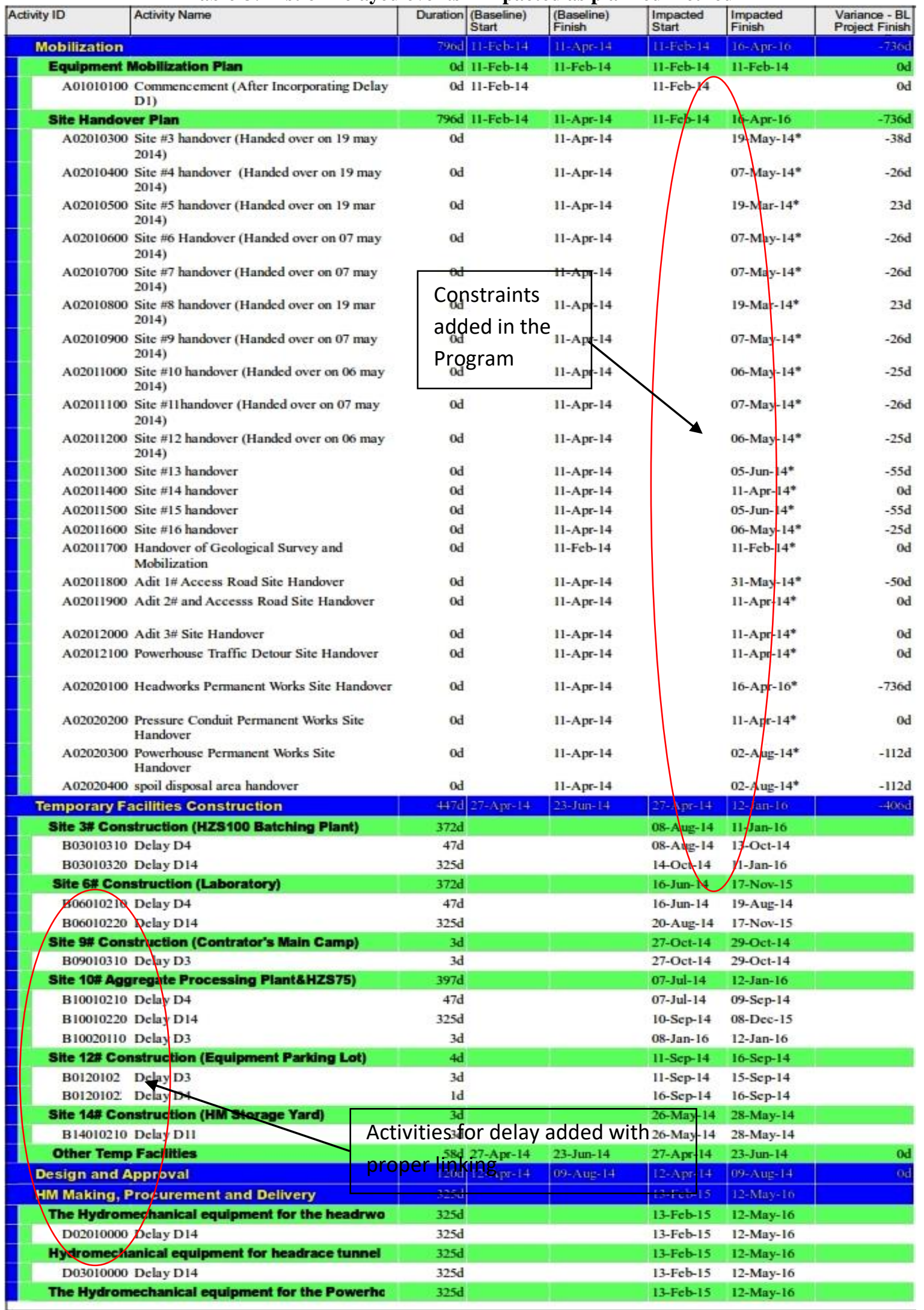




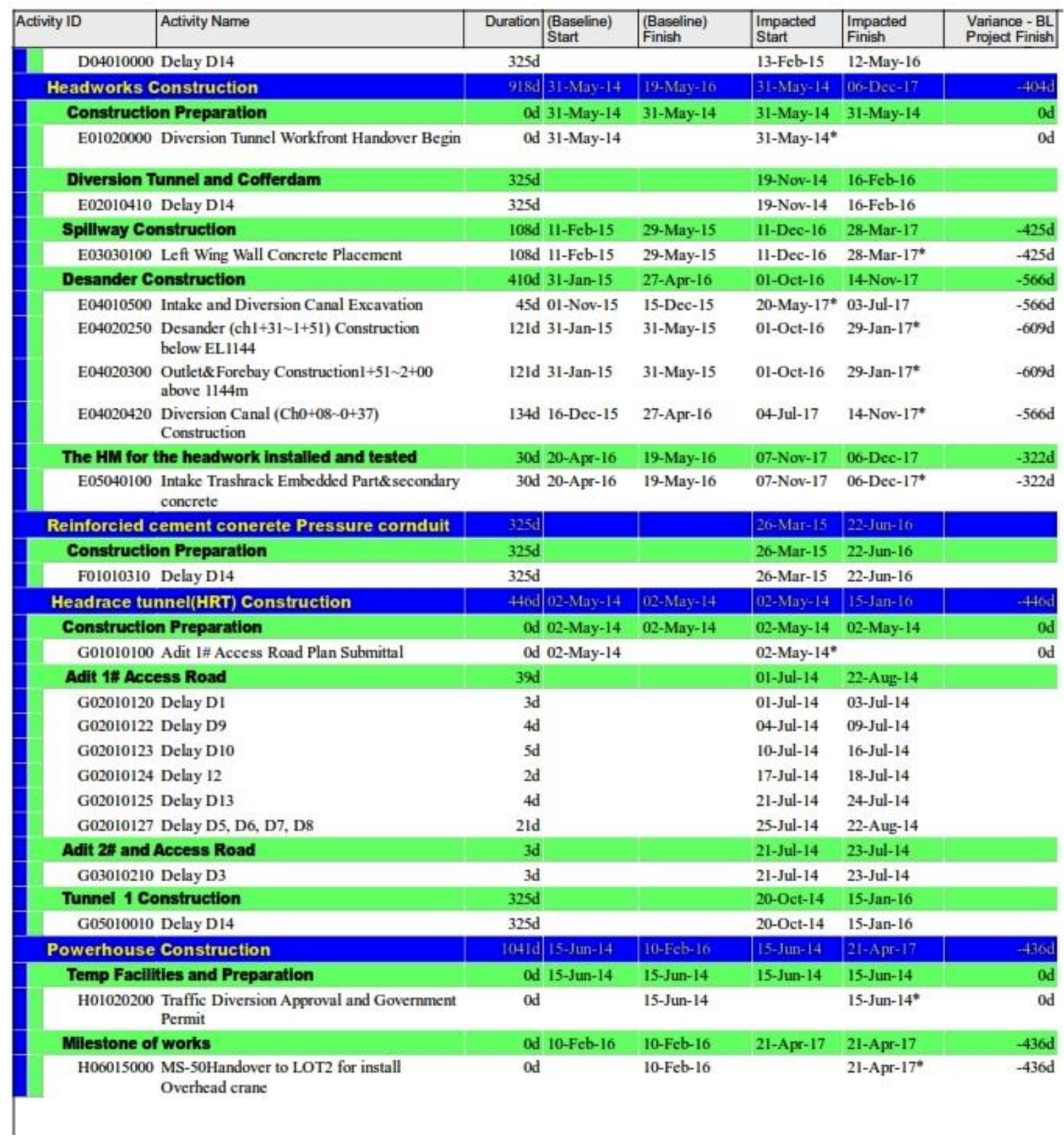

The delay events as shown above were then linked with the respective activities which are affected by those delay. The illustrationbelow will make it clearer:

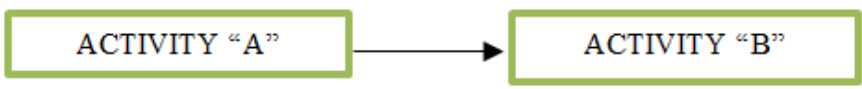

(Baseline Program before impacting delay)

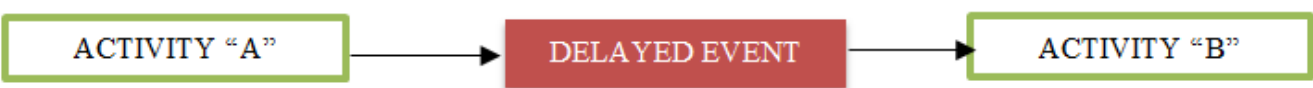

(Baseline Program after impacting delay)

Theprogram is then scheduled/recalculated and the scheduled program is compared with the base schedule. The difference in the completion date is observed. After impacting the delay as mentioned above it was observed that the new completion date became $19^{\text {th }}$ February 2019. 
Table-4: Project Completion date comparison; impacted as-planned v/s approved baseline Schedule

\begin{tabular}{|l|l|l|}
\hline & As per approved Baseline Program & As per Impacted as planned Program \\
\hline Project Completion & 9th June 2017 & $19^{\text {th }}$ February 2019 \\
\hline Project Duration & 1215 days & 1834 days (From original Commencement date) \\
\hline Additional days proposed: $(1936-1215)=620$ days \\
\hline
\end{tabular}

\section{Advantages}

In this method, there is a linkage between previous approved baseline schedule and the newly delay Impacted Program. Delays which are incurred from employers side has been incorporated in the schedule. Delay caused by the contractor were not introduced in the new revised schedule since those delays are non-excusable in nature. In general, the contractor have to accelerate the pace of the work to meet the intended completion target if the delays happened solely from their side only. The program is relatively easy to prepare and understand. Actual site progress and updated program is not required. The total float has been considered when impacting the delay. This type of DAT is preferred if the regular progress updates are not available.

\section{Disadvantages/Limitation}

The major limitationobserved in this method is that the concurrent delays were not addressed. In our case study, for instance, at one hand, the employer was unable to hand over the head-works site to the contractor while in other hand, due to the financial crisis and improper internal management, the contractor was not able to mobilize its manpower and machinery to the head-works site particularly. So it seems that both party are liable for this delay. Concurrent delay is excusable and non-compensable in general. However, it requires subjective judgment to some degree and has to be sort out by proper negotiations. If such delays are impacted in the program, it simply either tends to drag the final completion date or use the float if available which means that this method assumes that the time extension must be granted to the Contractor in case of concurrent delay.

Similarly, if there are multiple delays occurred in the site or if only portion of any site is disturbed, it is very difficult to show it in program. In our case study, the access road to Adit 1 has been disturbed several times. Sometime the full section has been stopped while in most of the cases, work stopped in certain chainages only. To incorporate or not to incorporate the stoppage/delays occurred in the portion of the site is also subjective.

The actual site condition and the real progress is not incorporated in the program so the schedule after incorporating delays did not reflect the actual site condition. The links in the approved baseline program must be very accurate and realistic. Otherwise the result will be misleading.

\section{Delay Analysis by using Time Impact Analysis method}

Correspondences related to the schedules and the periodic progress reports were used as primary data for the analysis purpose. The delays that are caused from the employer's side, delays caused due to the factors which were beyond the control of the employer and the contractor and the concurrent delays are considered for further analysis. Referring the correspondence between the employer and the contractor, the delay events, the effected duration and the area impacted by those delays were extracted which is presented in table labove.

The approved original Schedule is kept as baseline Schedule for the first fragnet. The 'networked' baseline schedule was first updated with progress to a point in time just before the delay event arose. For the succeeding fragnets, the preceding delay impacted and updated schedules were used as baseline schedule. For instance, original baseline schedule has been considered as a baseline schedule for fragnet 1; updated and delay impacted schedule uptofragnet 1 has been considered as a baseline schedule for fragnet 2 and so on.

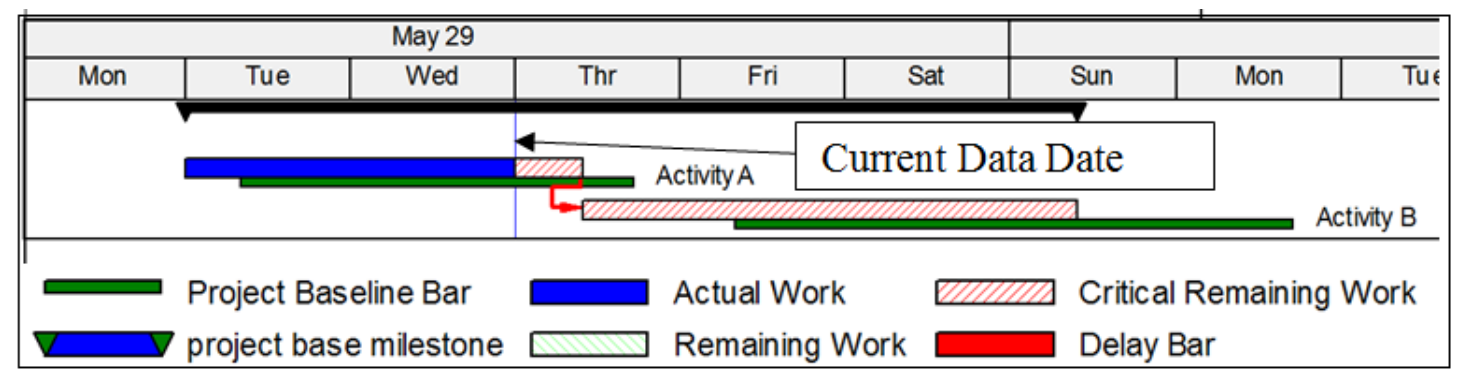

Fig-3: Illustration of progress updates before Impacting Delay

The delay events are then introduced into the schedule to establishthe likely impact on completion date, given the status of the works at the timethe delay event arose. In other word, the as-built status of the project, incorporating actual start/finish dates, changes, delays and impacts, is established up to the impact date and the schedule is recalculated. The as-planned or uncompleted portion of the schedule then forecasts the 
work remaining to be completed. The estimated impact of any delay-causing event can then be assessed by comparing the newly established completion date to the previous as-planned completion date.

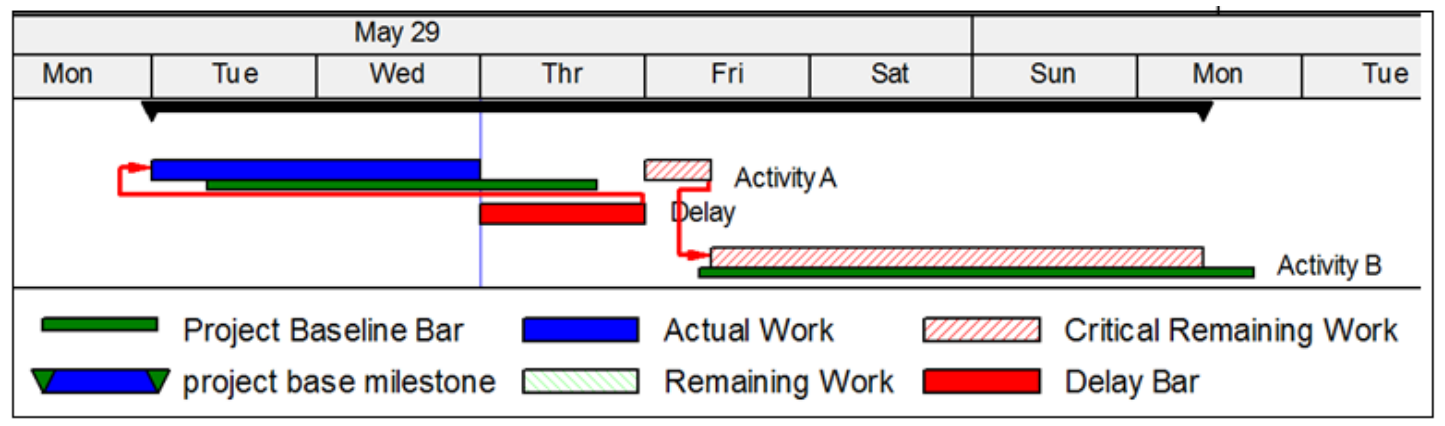

Fig-4: Illustration of progress updates after Impacting Delay

This is an iterative process repeated for each and everydelay causing event mentioned in Table- 1 and finally the total delay attributable to the employer and the contractor is calculated.

\section{Fragnet 1 - Delay D3 (11th Feb 2014 to 22nd July 2014)}

Table 4.7: Fragnet 1 - Delay D3

\begin{tabular}{|l|l|l|}
\hline (A) & Project Completion date as per approved original baseline program & 09 June 2017 \\
\hline (B) & As per progress updated program (upto 22 ${ }^{\text {nd }}$ July 2014) before impacting delay & 06 July 2017 \\
\hline (C) & As per progress updated program (upto 22 ${ }^{\text {nd }}$ July 2014) after impacting delay & 06 July 2017 \\
\hline (D)** & Delay occurred due to the Owner & $\begin{array}{l}=(A)-(B) \\
=27 \text { days }\end{array}$ \\
\hline
\end{tabular}

**After updating the program and impacting the delay, it is observed that the non-handing over of the site no\#13 (Temporary site) to the contractor in time has

\section{Delay Due to D1 and D2}

The delay D1 and D2 has already been incorporated in original approved schedule. The commencement date, 11th February 2014, was considered after incorporating D1.

\section{Fragnet 2- Delay D4 (22nd July 2014 to 02nd August 2014)}

Table 4.8: Fragnet 2-Delay D4

\begin{tabular}{|l|l|l|}
\hline (A) & Project Completion date as per updated program upto 22 ${ }^{\text {nd }}$ July 2014 & 06 Jul 2017 \\
\hline (B) & As per progress updated program (upto 02 ${ }^{\text {nd }}$ August 2014) before impacting delay D4 & 18 July 2017 \\
\hline (C) & Delay occurred due to the Contractor & $\begin{array}{l}=(\text { A)-(B) } \\
=12 \text { days }\end{array}$ \\
\hline (D) & $\begin{array}{l}\text { As progress updated } \\
\text { (upto 02 }\end{array}$ program & 17 Oct 2017 \\
\hline (E) & Total Delay & $\begin{array}{l}=(\mathrm{D})-(\mathrm{A}) \\
=83 \text { days }\end{array}$ \\
\hline (F) & Delay to Owner's causeupto the end of Fragnet 1 & $\begin{array}{l}\text { (E)-(C) } \\
=71 \text { days }\end{array}$ \\
\hline
\end{tabular}

The stoppage of whole of the works occurred from 02 August due to devastating landslide at Jure (Delay D4). However, after the completion of the Bailey bridge (Activity ID E020102000 of the original changed the critical path and has shifted the completion date of the project. Hence the delay occurred is due to owner's delay in handing over of the site.

\begin{tabular}{|c|c|c|c|c|c|c|}
\hline Activity ID & Activity Name & Duration & \begin{tabular}{|l} 
(Baseline) \\
Start
\end{tabular} & \begin{tabular}{|l} 
(Baseline) \\
Finish
\end{tabular} & Actual Start & Actual Finish \\
\hline \multicolumn{2}{|c|}{ Diversion Tunnel and Cofferdam } & 930d & 31-May-14 & 21-Dec-16 & 31-May-14 A & $16-$ Feb-17 \\
\hline E02010100 & Diversion Tunnel Workfront and Site Handover & $15 d$ & 31-May-14 & 14-Jun-14 & 31-May-14 A & 14-Jun-14 A \\
\hline E02010200 & Diversion Tunnel Bailey Bridges Up/Downstream & $50 \mathrm{~d}$ & 31-May-14 & 19-Jul-14 & 31-May-14 A & 19-Jul-14 A \\
\hline E02010210 & Delay D4 & $47 \mathrm{~d}$ & & & 02-Aug-14 & 17-Sep-14 \\
\hline E02010300 & Diversion Tunnel Excavation and Support & $15 d$ & $20-J u l-14$ & 03-Aug-14 & 18-Sep-14 & $02-0 c t-14$ \\
\hline
\end{tabular}


The Contractor's delay in this regard has been considered and therefore the delay due to Owner was:

71 days - (02 Aug 2017-19 July 2014)

$=(71-14)$ days

$=57$ days

Fragnet 3- Delay D5 and D8 (11th August 2014 to 31st October 2015)

Table 4.9: Fragnet 3-Delay D5 and D8

\begin{tabular}{|l|l|l|}
\hline (A) & Project Completion date as per updated program upto 02 ${ }^{\text {nd }}$ August 2014 & 17 October 2017 \\
\hline (B) & As per updated program (upto31 ${ }^{\text {st }}$ October 2014) before impacting delay & 29 November 2017 \\
\hline (C) & Delay occurred due to the Contractor & $\begin{array}{l}=(A)-(B) \\
=43 \text { days }\end{array}$ \\
\hline (D) & As per updated program (upto31 $1^{\text {st }}$ October 2014) after impacting delay & 29 November 2017 \\
\hline (E) & Total Delay & $\begin{array}{l}=(\text { D)-(A) } \\
=43 \text { days }\end{array}$ \\
\hline (F) & Delay to Owner's cause & $\begin{array}{l}\text { (E)-(C) } \\
=0 \text { days }\end{array}$ \\
\hline
\end{tabular}

The delay D5 and D8 consumed the available float and they did not lie in critical path. The critical path was same as in previous fragnet. The delay caused in excavation of diversion tunnel was the driving factor to shift the completion date. In this fragnet, the shifting of completion date was due to inefficiency of the contractor only.

\section{Delay Due to D6 and D7}

Both D6 and D7 are contemporaneous delay and has already been included in delay fragnet 2 .

\section{Fragnet4- Delay due to D9 and D10 (31 ${ }^{\text {st }}$ October to $01^{\text {st }}$ December 2014)}

No substantial delay occurred during this fragnet except minor stoppage of the works in the ADIT 1 area.

\begin{tabular}{|l|l|l|}
\hline (A) & Project Completion date as per updated program upto 02 ${ }^{\text {nd }}$ August 2014 & 29 November 2017 \\
\hline (B) & As per updated program (upto $1^{\text {st }}$ December 2014) before impacting delay & 30 December 2017 \\
\hline (C) & As per updated program (upto $1^{\text {st }}$ December 2014) after impacting delay & 30 December 2017 \\
\hline (E) & Total Delay & $\begin{array}{l}=(\text { D)-(A) } \\
=32 \text { days }\end{array}$ \\
\hline
\end{tabular}

In this fragnet, Diversion tunnel construction is the driving activity for project completion. This delay is therefore attributable to the contractor.

\section{Fragnet5- Delay due to D14 (31st October to 24th April 2015)}

The project passed under several delays. Devastating Earthquake with magnitude 7.9 Richter scale and numerous aftershocks caused thereafter has substantially impacted the Work Progress. In addition the blockade by India in between this period has also impart the substantial delay in the Project. The Schedule has beenanalyzed during this interval. The observations made is presented in the table below:

Table-4.10: Fragnet4-Delay due to D14

\begin{tabular}{|l|l|l|}
\hline (A) & Project Completion date as per updated program upto $1^{\text {st }}$ December 2014 & 30 December 2017 \\
\hline (B) & As per updated program (upto25 $5^{\text {th }}$ April 2015) before impacting delay & 31 March 2018 \\
\hline (C) & Delay occurred before impacting Delay D14 & $\begin{array}{l}=(\mathrm{A})-(\mathrm{B}) \\
=90 \text { days }\end{array}$ \\
\hline (D) & As per updated program (upto25 ${ }^{\text {th }}$ April 2015) after impacting delay & 19 February 2019 \\
\hline (E) & Total Delay & $\begin{array}{l}=(\mathrm{D})-(\mathrm{A}) \\
=415 \text { days }\end{array}$ \\
\hline (F) & Delay to Delay D 14 (Earthquake and blockade in border) & $\begin{array}{l}\text { (E)-(C) } \\
=325 \text { days }\end{array}$ \\
\hline
\end{tabular}

During Progress update upto $25^{\text {th }}$ April 2015, it was observed that the critical path changed. The headworks activities were in the critical path due to delayed handover of the head-works site. In addition the Delay
D14 (the impact of devastating Earthquake and the blockade in the border) further pushed the project completion date to 20 February 2019. It is to be noted here that the head-works site was still not handed over 
to the Contractor till the collection of these data and information. The project management team was therefore inquired about the probable date of the handover of the head-works site. It was predicted that probably the site hand over will occur on $1^{\text {st }}$ May 2017. Thus putting constraint in the head-works handing over activity (Activity ID: A02020100) on1st May 2017, the project completion date shifted to 20 February 2019.

Hence the delay occurred due to Employer in this sub net is

$((\mathrm{C})+(\mathrm{F}))$ of table 4.8

$=90$ days +325 days

$=415$ days

\section{Total Delay Calculation}

Overall delay (OD)

$\sum \mathrm{EC}_{\mathrm{od}}=$ Difference of the project completion of the last Fragnet and that of approved baseline schedule $=(20$ Feb 2019-9 Jun 2017) = 621 days

Net delay occurred from Employer's side (EC) is:

$\sum \mathrm{EC}_{\mathrm{net}}=\sum$ (EC's of all fragnet $)=27+57+0+415=\mathbf{4 9 9}$ days.

Again,

Due to the devastating Earthquake, the Contractor literally demobilized all its resources from the site. After the resumption of work from $15^{\text {th }}$ March, the period for remobilization and restoration of temporary structure had to be provided to the contractor. Upon discussion with the project management officials, allocating 30 days for remobilization and restoration was recommended.
Therefore the contractor is liable for 529 days of time extension using this method.

\section{Comparative Summary}

Following table provides quick comparative review on the outcomes from the application of Different DATs:

Table 4.11: Delayed Duration comparison by using various DATs

\begin{tabular}{|c|c|c|c|c|c|}
\hline $\begin{array}{l}\text { S. } \\
\text { No }\end{array}$ & Description & $\begin{array}{l}\text { Impacted } \\
\text { Completion } \\
\text { date }\end{array}$ & $\begin{array}{l}\text { Delay due } \\
\text { to } \\
\text { Employer } \\
\end{array}$ & $\begin{array}{l}\text { Delay due to } \\
\text { Contractor }\end{array}$ & Total Delay \\
\hline 1 & $\begin{array}{l}\text { Contractors' proposed } \\
\text { Extension of time } \\
\text { from the revised } \\
\text { Schedule }\end{array}$ & 31 May 2019 & 721 days & Not mentioned & $\begin{array}{l}\text { Not applicable: the } \\
\text { revised program only } \\
\text { asks the time for } \\
\text { intended completion } \\
\text { date. }\end{array}$ \\
\hline 2 & $\begin{array}{l}\text { Delay analysis using } \\
\text { Impacted as planned } \\
\text { method }\end{array}$ & 19 Feb 2019 & 621 days & $\begin{array}{l}\text { Not mentioned; the } \\
\text { delays caused from } \\
\text { Employers side has only } \\
\text { been impacted }\end{array}$ & Not applicable \\
\hline 3 & $\begin{array}{l}\text { Delay Analysis using } \\
\text { Time Impact analysis } \\
\text { Method }\end{array}$ & 20 Feb 2019 & 529 days & 90 days & 621 days \\
\hline
\end{tabular}

Three different results were obtained by using three different techniques on a case study.

\section{CONCLUSION}

In this case study, the Contractor has not followed any of the DATs to claim for extension of time. The contractor has submitted its revised construction schedule as per the FIDIC conditions of contract and ask for time extension of 721 days. The revised construction schedule has no any link with the original approved base Schedule.

The use of Impacted as planned method shows the delay to 620.This method is conventional method and relatively easy. The major delays incurred due to employer's deficiencies and outside factors were all taken into consideration in this method. Total Floats were considered in this method. The delay incurred by the Contractor has not been incorporated in the impacted Schedule. Actual site condition and the progress were not considered in this method. Concurrent delay has also not been addressed.

In Time Impact Analysis method, the delays from the Contractor's side as well as delay incurred due to the Employer were distinctly defined. The actual site conditions and the progress update were considered in this method. In this method, analysis has been done using the subnet and hence getting more detailed and 
refined result. However, this method demands regular progress updates from the site. In the absence of progress data, it will be of no use. Furthermore, application of this method is relatively complicated and needs experienced planner.

None of the DATs is found to address all the delay occurrence events. It is found that the Time Impact analysis method is relatively more elaborate as it uses the actual site progress and the sub net for each delay occurring events were analyzed. However, pacing delays and the concurrent delays were not addressed by any of the Prospective method used above.

\section{Limitation of the Study}

- The claims for time extension have only been considered in this study. The other consequences occurred due to delay like increment in overhead costs and other intangible costs, time value of money and opportunity cost are not included in this study.

- There are multiple Contract packages in the project under study. Only the Contract package comprising of Civil and Hydro-mechanical Works has been considered in this study.

\section{REFERENCES}

1. Alnaas, K. A., Khalil, A. H., \& Nassar, G. E. (2014). Guideline for preparing comprehensive extension of time (EoT) claim. HBRC Journal, 10(3), 308-316.

2. Barry, D. (2009). Beware of the Dark Acts! Delay analysis and the problems with reliance on technology. (pp. 1-10). London: The Society of Construction Law 2009.

3. Arditi, D., \& Pattanakitchamroon, T. (2006). Selecting a delay analysis method in resolving construction claims. International Journal of project management, 24(2), 145-155.
4. Bureau of Indian Standards. (2013). Construction Project Management Guidelines-Part 2 Time Management. Bureau Of Indian Standards. Manak.

5. Society of Construction Law. (2002). The Society of Construction Law Delay and Disruption Protocol. Society of Construction Law. Wantage, Oxfordshire: Society of Construction Law.

6. Federation Internationale Des Ingenieurs-Conseils (FIDIC). (2010). Conditions of Contract for Construction. Federation Internationale Des Ingenieurs-Conseils (FIDIC).

7. Mishra, A. K., \& Bhandari, E. S. (2018). Performance assessment of ongoing construction projects under town development fund, Nepal. International Journal of Advanced Research in Civil \& Structural Engineering, 1(1\&2), 27-39.

8. Public Procurement Monitoring Office. (2014). Procurement of Works (NCB for above 6 Million Rupees). Public Procurement Monitoring Office. Kathmandu: Public Procurement Monitoring Office.

9. Keane, P., \& Caletka, A. (2015). Delay analysis in Construction Contract. Blackwell publishing Limited.

10. Agostinelli, S., Allison, J., Amako, K. A., Apostolakis, J., Araujo, H., Arce, P., ... \& Behner, F. (2003). GEANT4-a simulation toolkit. Nuclear instruments and methods in physics research section A: Accelerators, Spectrometers, Detectors and Associated Equipment, 506(3), 250-303.

11. Regmi, R., Berthelot, J., Winkler, P. M., Mivelle, M., Proust, J., Bedu, F., ... \& García-Parajó, M. F. (2016). All-dielectric silicon nanogap antennas to enhance the fluorescence of single molecules. Nano letters, 16(8), 5143-5151. 